Reviews

Somnologie $2020 \cdot 24: 90-96$

https://doi.org/10.1007/s11818-020-00250-z

Published online: 12 May 2020

(c) The Author(s) 2020

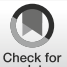

\author{
Svetlana Gorokhova' $\cdot$ Ingo Fietze ${ }^{2} \cdot$ Martin Glos $^{2}$ (D) $\cdot$ Thomas Penzel $^{2,3}$. \\ Migran Buniatyan ${ }^{4}$. Oleg Atkov ${ }^{1}$ \\ 'Russian Medical Academy of Postgraduate Education, Moscow, Russian Federation \\ ${ }^{2}$ Interdisciplinary Sleep Medicine Center, Charité-Universitätsmedizin Berlin, Berlin, Germany \\ ${ }^{3}$ Saratov State University, Saratov, Russian Federation \\ ${ }^{4}$ Research Clinical Center of the Russian Railways, Moscow, Russian Federation
}

\title{
On the use of actigraphy in clinical evaluation of diurnal blood pressure profile
}

with automatic detection of nighttime decrease values, rate of morning increase, and diurnal BP variability should support the calculation of diurnal BP profile.

$A B P M$ is the main method of measurement of diurnal BP profile. It may seem that it gives the physician comprehensive data on individual DBPP features. However, much attention is now paid to simultaneous registration of ABPM and diurnal motor activity (actigraphy) to receive additional information necessary for the correct interpretation of ABPM results and clinically significant decisionmaking $[8,9,18]$. Actigraphy is not a new technique; first devices were used in studies on human psychology and physiology in 1950s [42]. However, it remains rather unknown for many cardiologists and, therefore, it is insufficiently popular. This necessitates a discussion on some aspects of its application, particularly for the assessment of diurnal BP profile.

\section{Actigraphy}

Actigraphy is registration of motor activity by a device implementing a 3D accelerometer and position sensor (actimeter). Usually, long-time actigraphy is performed, with the patient constantly wearing the device from one day to two weeks. The actimeter is fastened to a moving part of body (wrist, ankle, breast) to enable activation of the recording of the amplitude and time of motion (- Fig. 1a). Two-dimensional sensors register both motion and body position, i.e., lying, standing, on the right, or on the left side (• Fig. 1b). It should be emphasized that although there are smartphone applications for actigraphy, only validated devices should be used for medical purposes. Computer algorithms process the record and detect periods of relative sleep (no activity) and vigilance (activity). Actigraphs with special analysis of movement pattern software additionally estimate various parameters of objective sleep-wake structure.

\section{ABPM plus actigraphy}

Synchronous monitoring of BP, activity, and body position provides the possibility of performing ABPM and actigraphy in the same time segments. It provides information on the state of the cardiovascular system in sleep and vigilance, and on the influence of body position changes and motion on BP and heart rate. The actigraphy in expert ABPM can therefore be used for precise, clock-independent calculation of nighttime and daytime BP, detection of BP changes during sleep, and finding connections between these changes and motor activity, body position, and breath disturbances during sleep, and the state of the autonomic nervous system.

Time-independent methods that reflect current vigilance and sleep are the most reliable for detection of daytime and nighttime periods and blood pressure. It is assumed that a person is vigilant during the astronomic day and is at rest 

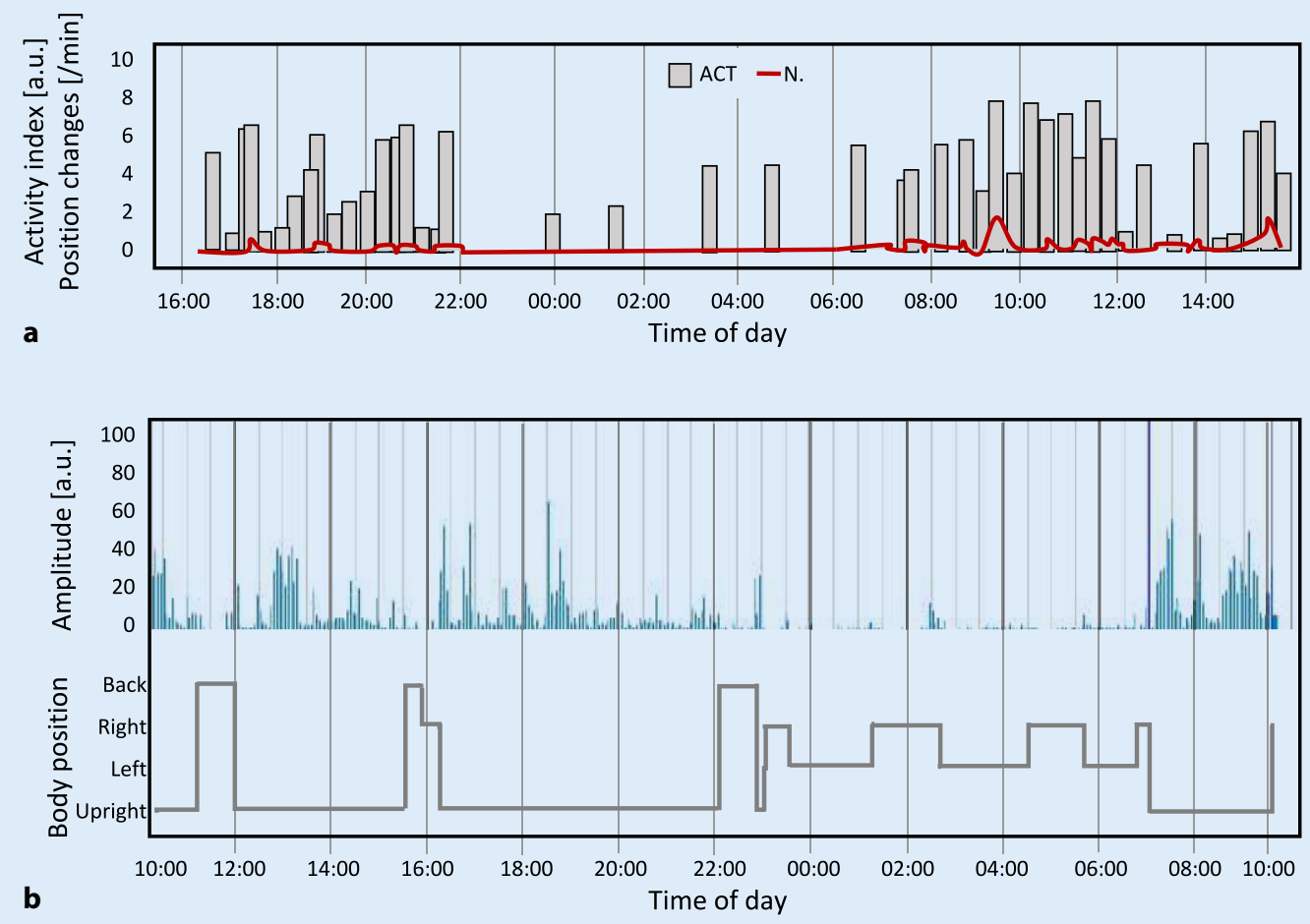

Fig. 14 Samples of actograms: a registration of motor activity index (ACT, beige bars) and number of position changes per minute ( $N$., red line); b simultaneous registration of motion amplitude (Amplitude, upper panel) and body position (lower panel)

and sleeps during the astronomic night. On the basis of the solar diurnal cycle, time-dependent methods of periodization were developed with fixed average daytime and nighttime periods. They differ somewhat with respect to the considered time periods, because concurrence with vigilance and sleep is important [35]. A broad interval with daytime lasting from $7 \mathrm{AM}$ to $10-11 \mathrm{PM}$ and nighttime from 10-11 PM to $7 \mathrm{AM}$, or a narrower interval with a daytime period from $10 \mathrm{AM}$ to $8 \mathrm{PM}$ and nighttime period from midnight or $1 \mathrm{AM}$ to $6 \mathrm{AM}$ is taken. Daytime and nighttime $\mathrm{BP}$ and DBPP values are calculated for these periods.

This general approach does not always reflect the reality of modern lifestyle. Obviously, sleep and night are not synonyms, and they are not always concurrent. It is well known that the onset of sleep and its duration vary from night to night and from person to person, due to individual behavior, household conditions, and stresses during the day. The duration and onset of sleep are also influenced by other factors, for example seasonal changes of light day [46]. Additionally, it is known that a high proportion of the total population has sleep disturbances (insomnia, hypersomnia, sleep apnea, restless legs syndrome, etc.), with impaired falling asleep, frequent nocturnal arousals, decreased total sleep duration, and impaired sleep quality $[10,22,52]$. It should be noted that the impairment of sleep duration and quality is associated with a higher risk of cardiovascular mortality, especially with arterial hypertension [21, 26, 37, 50]. Another important aspect is social deprivation of nighttime sleep, which is common in the working population and especially in shift workers [22]. - Fig. 2 shows periods of daytime sleep and nighttime activity in a patient working nightshifts.

To avoid errors in the detection of sleep periods, diaries are used in which patients note the times of falling asleep and arousals [18, 36]. However, these notes are not objective in most populations studied [27, 32]. It was found that the true time of sleep onset and wake differ from the time in diaries by $30 \mathrm{~min}$ on average and sometimes by more than $90 \mathrm{~min}$. • Fig. 3 shows a significant discrepancy between the rest period (8:15 PM to 7:45 AM, probably sleep) registered by actigraphy and the night period of ABPM based on patient's diary (11 PM to $7 \mathrm{AM}$ ).

Such cases to some extent explain insufficient reproducibility of DBPP values $[4,13]$. Eissa et al. [11] note that diaries used for the registration of motor activity are adequate only in $71 \%$ of patients, which leads to mistakes in classification of patients as non-dippers (less than 10\% drop in mean BP during sleep) in $32 \%$ of cases. For example, $23 \%$ of patients who were considered dippers based on their diaries were actually non-dippers. Butkevich et al. [5] showed that due to the variability of criteria of daytime and nighttime periods, re-classification of the status of patients is inevitable. The difference may be 35-69\%.

Muller et al. compared daytime and nighttime BP obtained by simultaneous diurnal actigraphy and by fixed daytime (7 AM to $10 \mathrm{PM}$ ) and nighttime (10 PM to $7 \mathrm{AM}$ ) periods [34]. It was found that the values of nighttime BP and diurnal index were significantly lower in cases of detection of night by actigraphy. Therefore, a question arises about the correlation of nocturnal BP decrease and BP decrease during sleep, which is important for the assessment of cardiovascular risk. Her- 
mida et al. [15-17] demonstrated that BP decrease during sleep confirmed by actigraphy is the most precise prognostic risk marker of cardiovascular events and renal failure in patients with arterial hypertension. The MAPEC prospective randomized blind study, in which 3344 patients were observed for over 5 years to find advantages of chronotherapy of arterial hypertension compared to standard therapy in conditions of outpatient BP control, showed that BP decrease during sleep, and not in fixed periods of astronomical night, was associated with a risk of cardiovascular events [15]. These results should not be ignored.

A meta-analysis by Taylor et al. [47] on heterogeneity of studies on the prognostic value of diurnal variability of $\mathrm{BP}$ pays much attention to the differences in methodological approaches to the measurement of time of sleep and vigilance. It was noted that the most precise results are based on the registration of motor activity. International recommendations on outpatient diurnal BP monitoring [20] published in 2013 state that diurnal BP profile and diurnal index should be based on BP values measured during sleep and not in the astronomical night, and current actigraphy data should be used. It is expressly stated that the conclusions about diurnal BP profile made on time-dependent ABPM should be avoided. However, this is not reflected in the position taken by the ESH $[35,36]$.

The moderate position of the ESH is probably connected to current technical and methodological limitations and especially to insufficient software for the calculation of BP decrease during sleep. Although actigraphy is an option in modern ABPM measurement devices, DBPP values are automatically calculated from standard nighttime intervals and not sleep periods. This issue can be solved by manual input of sleep time intervals, as in the case of patients' diaries.

\section{Sleep disturbances and BP profiles}

The problem of sleep disturbances is well described in reviews $[3,14,38]$. There is a high (35-80\%) prevalence of arterial hypertension in OSA and OSA is diag-

Somnologie $2020 \cdot 24: 90-96$ https://doi.org/10.1007/s11818-020-00250-z

(c) The Author(s) 2020

S. Gorokhova · I. Fietze · M. Glos · T. Penzel · M. Buniatyan · O. Atkov

On the use of actigraphy in clinical evaluation of diurnal blood pressure profile

\section{Abstract}

A disturbed diurnal blood pressure profile is one of the most important risk factors of cardiovascular diseases. This review analyzes the use of simultaneous diurnal ambulatory blood pressure monitoring (ABPM) and motion activity monitoring (actigraphy) to obtain additional information for correct interpretation of ABPM results in clinically significant decision-making. The article considers practical aspects of actigraphy in expert ABPM for clock-independent calculation of the parameters of nighttime and daytime blood pressure (BP); detection of $\mathrm{BP}$ changes during sleep; connection with respiratory disturbances during sleep, motion activity, and body position; and sleep deprivation in shift workers. Original illustrations of simultaneous ABPM and actigraphy are provided.

Keywords

Sleep disturbances · Sleep profile $\cdot$ Ambulatory blood pressure monitoring · Arterial hypertension - Blood pressure dipping

\section{Einsatz der Aktigraphie zur klinischen Beurteilung des tageszeitabhängigen Blutdruckprofils}

\section{Zusammenfassung}

Ein gestörtes tageszeitabhängiges Blutdruckprofil ist einer der wichtigsten Risikofaktoren für Herz-Kreislauf-Erkrankungen. In der vorliegenden Übersichtsarbeit wird die Bedeutung der gleichzeitigen Durchführung des ambulanten Blutdruckmonitorings (ABPM) und der Messung der Bewegungsaktivität (Aktigraphie) beschrieben. Durch die Aktigraphie werden zusätzliche Informationen für die korrekte Interpretation des ABPM gewonnen, die zu klinisch relevanten Entscheidungen beitragen. In diesem Artikel werden praktische Aspekte der Aktigraphie in der Anwendung durch Experten bei ABPM zur uhrzeitunabhängigen Berechnung der
Parameter des Blutdrucks (BP) am Tag und in der Nacht betrachtet, zur Erkennung von BP-Veränderungen während des Schlafs, zum Zusammenhang mit Atmungsstörungen während des Schlafs, zur Bewegungsaktivität und zur Körperposition sowie zum Schlafentzug bei Schichtarbeitern. Originalabbildungen der durchgeführten ABPM und Aktigraphie illustrieren exemplarisch die Daten.

\section{Schlüsselwörter}

Schlafstörungen · Schlafprofil · Ambulantes Blutdruckmonitoring · Arterielle Hypertonie . Blutdruckabsenkung nosed in $40 \%$ of persons with hypertension. Both conditions are mutually exacerbating. Similar observations were made in subjects with short sleep duration. According to prospective studies and epidemiological data, the probability of arterial hypertension is $32 \%$ higher in persons with short $(\leq 5 \mathrm{~h})$ nighttime sleep [7, 24]. The Monitoring Project on Risk Factors and Chronic Diseases in the Netherlands (MORGEN) and the Prospective Urban Rural Epidemiology (PURE) study that collects data among residents of 25 countries demonstrated that persons with $\leq 6 \mathrm{~h}$ of nighttime sleep have a higher total cardiovascular risk and higher risk of coronary heart disease compared to those who sleep 7-8h [21, 50]. In case of simultaneous deterioration of sleep quality, these risk indicators increase to 63 and 79\%, respectively. Disturbed diurnal BP profile in this category of patients is probably an additional contribution to the increased risk [23, 28].

Actigraphy with the use of special analytical programs enables detection of the time of sleep onset and arousal, duration, effectiveness, and latency of sleep, and arousals and vigilant periods after the onset of sleep. The records may last over a week (sometimes up to two weeks), which increases the informative value of the study and makes the method an exceptional diagnostic tool for patients with 


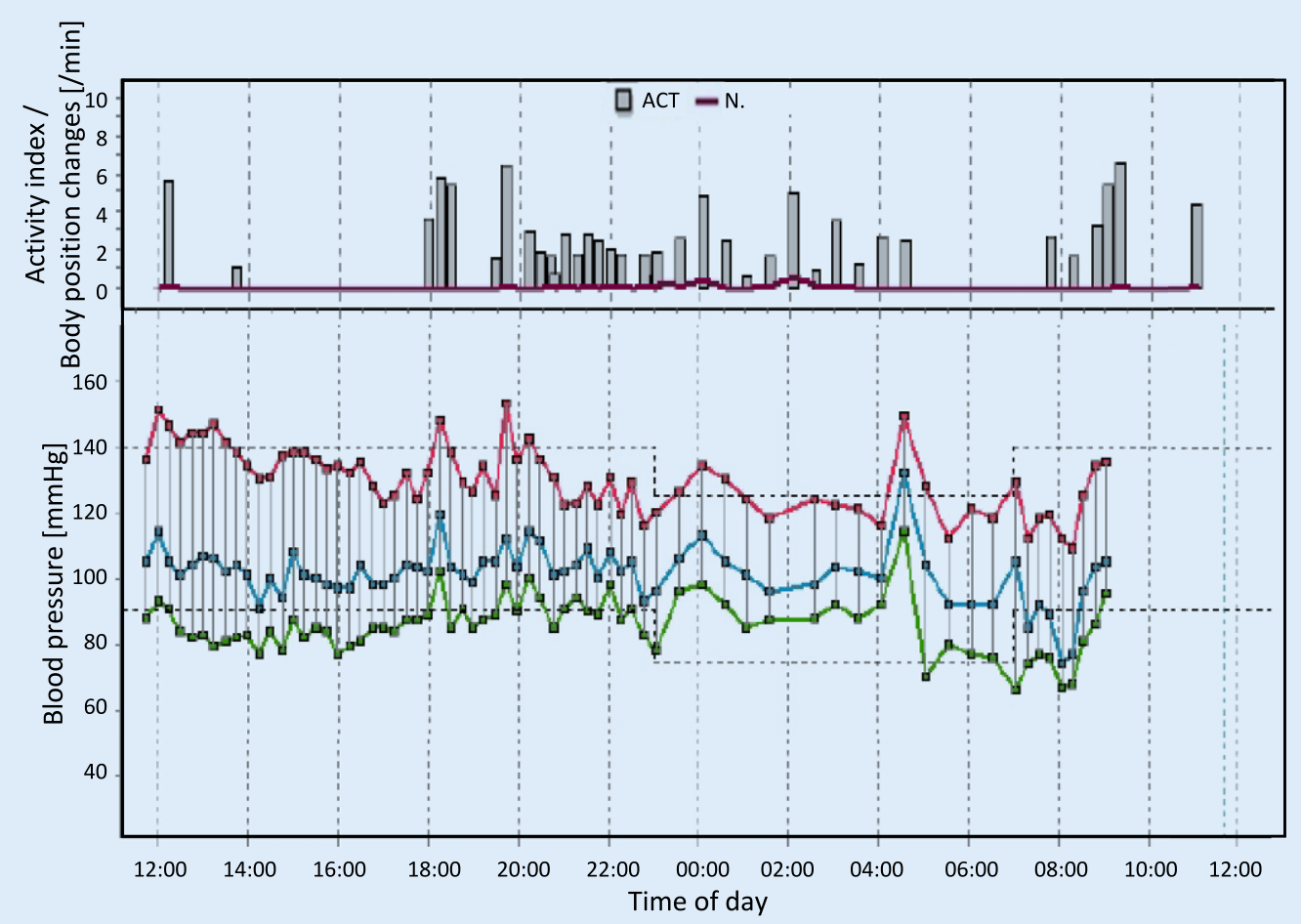

Fig. $2 \triangleleft$ Registration of motor activity ( $A C T$, gray bars, upper panel) and number of body position changes per minute (N., red line, upper panel) as well as ambulatory blood pressure monitoring (ABPM, lower panel) of systolic values (red line), mean values (blue line), and diastolic values (green line) in a nightshift worker. It is shown that sleep corresponds to periods from 12:15 to $17: 45 \mathrm{~h}$ The patient is vigilant during a standard night period for ABPM records (23:00 to 07:00 h)

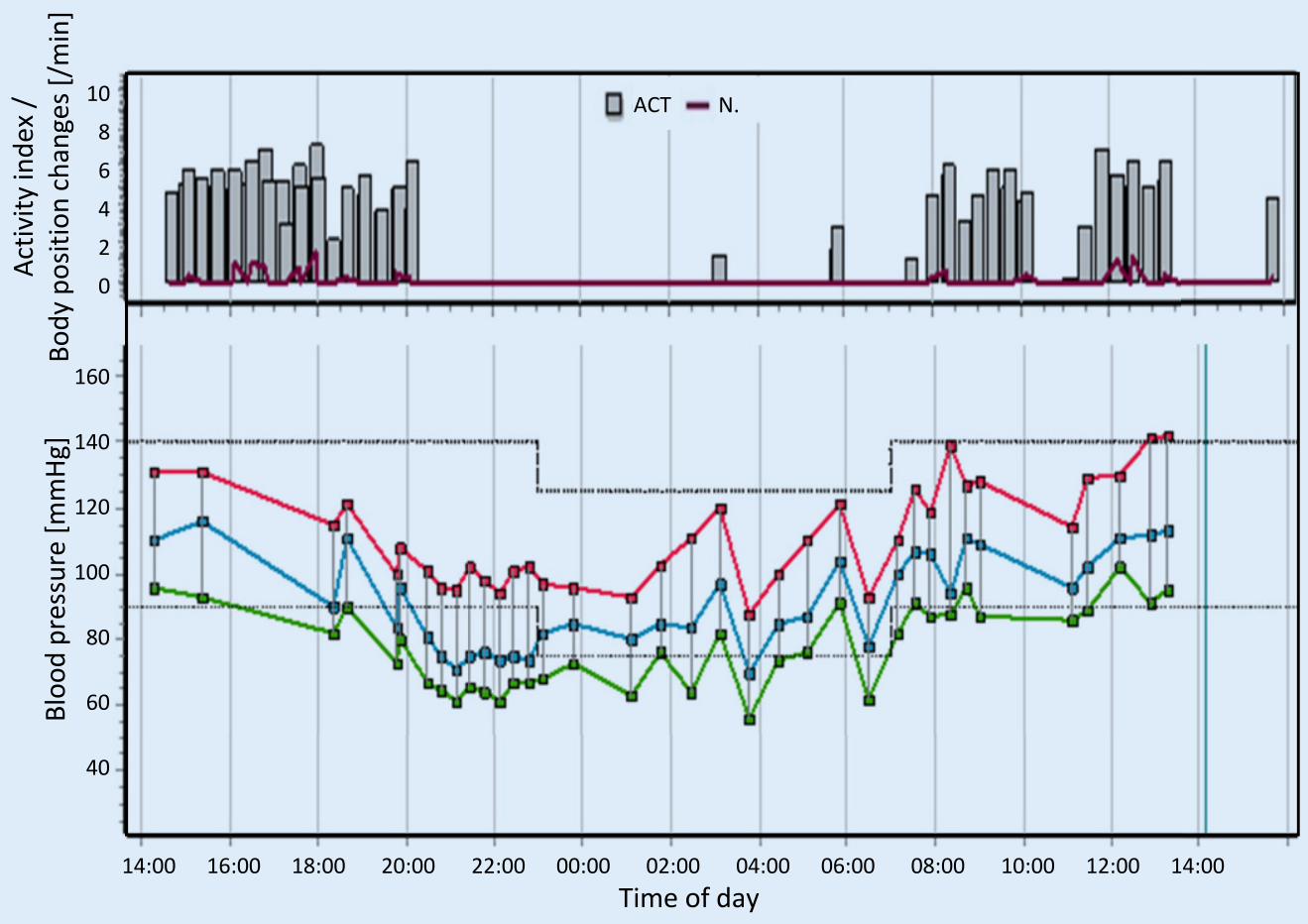

Fig. $3<$ A fragment of the record of diurnal motor activity monitoring ( $A C T$, gray bars, upper panel) and number of body position changes per minute (N., red line, upper panel) as well as ambulatory blood pressure monitoring ( $A B P M$, lower panel) of systolic values (red line), mean values (blue line), and diastolic values (green line) in patient $R$, 53 years old. A discrepancy is shown between the night period detected by ABPM (23:00 to 07:00 h) and sleep period (20:15 to $07: 45 \mathrm{~h}$ ) detected by actigraphy 


\begin{tabular}{|c|c|c|c|c|c|c|c|c|c|}
\hline Time & $\begin{array}{l}\text { Body } \\
\text { position }\end{array}$ & Activity & $\mathrm{N}$ & $\begin{array}{c}\text { Systolic } \\
\text { ABPM }\end{array}$ & $\begin{array}{l}\text { Mean } \\
\text { ABPM }\end{array}$ & $\begin{array}{c}\text { Diastolic } \\
\text { ABPM }\end{array}$ & PP & HR & DPI \\
\hline $19: 13$ & 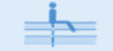 & 0.5 & 0.0 & 122 & 107 & 95 & 27 & 87 & 106 \\
\hline $19: 28$ & 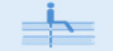 & 2.8 & 0.0 & 103 & 71 & 64 & 39 & 83 & 85 \\
\hline $19: 43$ & in & 3.5 & 0.2 & 113 & 76 & 66 & 47 & 80 & 90 \\
\hline $19: 58$ & $m$ & 4.4 & 0.2 & 122 & 93 & 76 & 46 & 78 & 95 \\
\hline $20: 13$ & $p$ & 5.8 & 0.4 & 92 & 77 & 67 & 25 & 85 & 78 \\
\hline $20: 28$ & $p$ & 6.9 & 1.2 & 99 & 73 & 66 & 33 & 84 & 83 \\
\hline $20: 43$ & $\frac{i}{p}$ & 6.2 & 0.4 & 111 & 86 & 74 & 37 & 71 & 79 \\
\hline $21: 09$ & $p$ & 6.7 & 0.2 & 107 & 71 & 63 & 44 & 75 & 80 \\
\hline $21: 24$ & $-\sim$ & 1.8 & 0.0 & 110 & 80 & 70 & 40 & 66 & 73 \\
\hline $21: 29$ & $-\sim$ & 6.1 & 0.3 & 108 & 81 & 70 & 38 & 66 & 71 \\
\hline $21: 47$ & $-\sim$ & 0.0 & 0.0 & 102 & 77 & 64 & 38 & 69 & 70 \\
\hline $22: 09$ & $-\sim$ & 0.0 & 0.0 & 104 & 82 & 70 & 34 & 59 & 61 \\
\hline
\end{tabular}

Fig. $4<$ Data sheet of simultaneous registration of body position; motor activity (Activity); number of body position changes per minute $(N)$; systolic, mean, and diastolic ambulatory blood pressure monitoring $(A B P M)$ values; pulse pressure $(P P)$; heart rate $(H R)$; and double product index $(D P I=[S B P \times P R] / 100)$ values in patient $A, 30$ years old. The orthostatic hypotension at $20: 13 \mathrm{~h}$ is shown according to the records of activity and body position sleep disturbances. The gold standard for diagnostics of sleep disturbances is now polysomnographic study, which is expensive and difficult to accomplish in longterm (multiple day) monitoring. Consensus papers state that actimetry can be used as an alternative for OSA diagnostics, as a pre-screening, or if polysomnography is impossible. It is also used to detect circadian sleep disturbances and dyssomnias in people with insomnia, including when this connected with depression, and to detect severe sleep disturbances that require treatment $[1,2,6$, 33, 44].

The use of actigraphy for this purpose is advisable because of significant motor activity during sleep and decreased duration of motionless periods in insomnias [45]. Motor activity in persons with OSA is associated with sleep fragmentation with episodes of obstructive apnea or hypopnea [31]. Sleep fragmentation with motor activity in OSA on the other hand correlates with a decreased respiratory function detected by peak rate [31, 40].

The sensitivity of actigraphy for the detection of arousals in patients with OSA is not high ( $48 \%$ compared with $98 \%$ sensitivity for the detection of sleep periods in general) [25]. However, this method is highly (>90\%) specific. This means that although actigraphy per se does not detect respiratory disturbances, it can indirectly objectify severe OSA and helps to assess sleep efficiency. The application of actimetry with ABPM may improve the selection of patients for polysomnographic study or cardiorespiratory monitoring, and objectify the analysis of nighttime BP increases [45].

It seems that the detection of restless legs syndrome is of a similar importance for expert evaluation of BP profile. Some studies revealed that both primary and secondary syndrome is associated with arterial hypertension, which is found in $30 \%$ of such patients [49]. It was shown that restless legs syndrome is more frequently detected in patients with insufficient nighttime BP decrease, and that they have a more severe form of the syndrome [12, 43, 48].

\section{Other factors influencing BP profiles}

Actigraphy also helps in revealing other factors that influence blood pressure, for example body position. Clinically significant orthostatic and clinostatic hypoand hypertension are characterized by a decreased or increased BP after the transition to a standing or a laying position, respectively. A connection also was found between postural or orthostatic BP changes during the day and various profiles of nighttime BP decrease in asymptomatic patients without drug treatment. Postural hypotony and a nondipping profile deteriorate parameters of cardiovascular risk [13].

For obvious reasons, postural conditions are very hard to detect. Patients rarely measure BP due to sudden sickness on the background of hypo- and hypertension, which is accompanied by dizziness, weakness, and sometimes syncope. BP measurement by another person is not always possible in such moments, because the episodes are short and transient. Therefore, special examination is required to find the link between BP and postural changes. Actigraphy is absolutely indicated in this case, because comparison of the time of the hypo- or hypertension episode and registered standing up enables true episodes to be revealed.

- Fig. 4 shows an example of the short period of orthostatic hypotension. 


\section{Practical aspects}

In patients receiving $\mathrm{ABPM}$, actigraphy may help to:

1. monitor the activity and its clinical evolution in an outpatient setting;

2. monitor sleep problems, mainly sleep latency and efficiency.

\section{Research agenda}

Studies of patients with ABPM are necessary to:

1. find out whether actigraphy is an efficient tool for monitoring of activity and sleep in an ambulatory setting;

2. investigate actigraphic motor activity during $24 \mathrm{~h}$;

3. explore whether and how altered actigraphic parameters should be treated.

\section{Conclusion}

Expert assessment of diurnal BP profile requires a precise and objective daytime periodization to evaluate the individual profile of BP decrease phases and to find the causes of insufficient $B P$ decrease during sleep. To do this, traditional ABPM should be enhanced with methods of motion activity registration, i.e., actigraphy. Analysis of the data of both measurements makes it possible to verify sleep and vigilance periods and detect some sleep disturbances, periods of motor activity, and changes in body position connected with BP changes, which are significant parameters of diurnal profile in patients with arterial hypertension.

\section{Corresponding address}

\section{Dr. Martin Glos}

Interdisciplinary Sleep Medicine Center, Charité-Universitätsmedizin Berlin Charitéplatz 1, 10117 Berlin, Germany martin.glos@charite.de

Funding. Open Access funding provided by Projekt DEAL.

\section{Compliance with ethical guidelines}

Conflict of interest. I. Fietze has received research grants from Actelion, Eisai, Heinen \& Löwenstein, Jazz Pharmaceuticals, Philips/Respironics, Resmed, Somnodent, UCB, Vanda. M. Glos has received a research grant from Phasya. T. Penzel has received research grants from Heinen \& Löwenstein, Itamar, Philips/Respironics, Resmed, Somnodent and was partially supported by Russian Federation Government grant No 075-15-2019-1885. S. Gorokhova, M. Buniatyan and $\mathrm{O}$. Atkov declare that they have no competing interests. The authors alone are responsible for the content and writing of the paper. All authors have read and approved the manuscript.

For this article, no studies with human participants or animals were performed by any of the authors. All studies performed were in accordance with the ethical standards indicated in each case.

Open Access. This article is licensed under a Creative Commons Attribution 4.0 International License, which permits use, sharing, adaptation, distribution and reproduction in any medium or format, as long as you give appropriate credit to the original author(s) and the source, provide a link to the Creative Commons licence, and indicate if changes were made. The images or other third party material in this article are included in the article's Creative Commons licence, unless indicated otherwise in a credit line to the material. If material is not included in the article's Creative Commons licence and your intended use is not permitted by statutory regulation or exceeds the permitted use, you will need to obtain permission directly from the copyright holder. To view a copy of this licence, visit http://creativecommons.org/licenses/by/4.0/.

\section{References}

1. Ancoli-Israel S, Cole R, Alessi C et al (2003) The role of actigraphy in the study of sleep and circadian rhythms. Sleep 26:342-392

2. Anonymous (2019) Actigraphy. In: Cross PB (ed) Medical policy-2.01.73. Premera Blue Cross, Seattle, WA, p 9

3. Bathgate CJ, Fernandez-Mendoza J (2018) Insomnia, short sleep duration, and high blood pressure: recent evidence and future directions for the prevention and management of hypertension. Curr Hypertens Rep 20:52

4. BoggiaJ,LiY,ThijsLetal(2007) Prognosticaccuracy of day versus night ambulatory blood pressure: a cohort study. Lancet 370:1219-1229

5. Butkevich A, Phillips RA, Sheinart KF et al (2000) The effects of various definitions of dipping and daytime and night-time on the characterization of $24 \mathrm{~h}$ profiles of blood pressure. Blood Press Monit 5:19-22

6. Buysse DJ, Ancoli-Israel S, Edinger JD et al (2006) Recommendations for a standard research assessment of insomnia. Sleep 29:1155-1173

7. Chandola T, Ferrie JE, Perski A et al (2010) The effect of short sleep duration on coronary heart disease risk is greatest among those with sleep disturbance: a prospective study from the Whitehall Il cohort. Sleep 33:739-744

8. Crespo C, Fernandez JR, Aboy M et al (2013) Clinical application of a novel automatic algorithm for actigraphy-based activity and rest period identification to accurately determine awake and asleep ambulatory blood pressure parameters and cardiovascular risk. Chronobiol Int 30:43-54

9. Cummings MK, Ingham DP, Rosborough TK (2017) Application and effects of ambulatory blood pressure monitoring in primary care. J Minneap Heart Inst Found 1:101-107

10. Daley M, Morin CM, Leblanc M et al (2009) The economic burden of insomnia: direct and indirect costs for individuals with insomnia syndrome, insomnia symptoms, and good sleepers. Sleep 32:55-64

11. Eissa MA, Yetman RJ, Poffenbarger T et al (1999) Comparison of arbitrary definitions of circadian time periods with those determined by wrist actigraphy in analysis of ABPM data. J Hum Hypertens 13:449-453

12. Erden EC, Erden I, Turker Y et al (2012) Incremental effects of restless legs syndrome on nocturnal blood pressure in hypertensive patients and normotensive individuals. Blood Press Monit 17:231-234

13. Fagard RH, De Cort P (2010) Orthostatic hypotension is a more robust predictor of cardiovascular events than nighttime reverse dipping in elderly. Hypertension 56:56-61

14. Gottlieb DJ, Craig SE, Lorenzi-Filho G et al (2013) Sleep apnea cardiovascular clinical trials-current status and steps forward: the international collaboration of sleep apnea cardiovascular trialists. Sleep 36:975-980

15. Hermida RC, Ayala DE, Mojon A et al (2011) Decreasing sleep-time blood pressure determined by ambulatory monitoring reduces cardiovascular risk. J Am Coll Cardiol 58:1165-1173

16. Hermida RC, Ayala DE, Mojon A et al (2012) Sleeptime blood pressure and the prognostic value of isolated-office and masked hypertension. Am J Hypertens 25:297-305

17. Hermida RC, Ayala DE, Mojon A et al (2014) Sleeptime ambulatory blood pressure as a novel therapeutic target for cardiovascular risk reduction. JHum Hypertens 28:567-574

18. Hermida RC, Ayala DE, Smolensky MH et al (2016) Chronotherapy with conventional blood pressure medications improves management of hypertension and reduces cardiovascular and stroke risks. Hypertens Res 39:277-292

19. Hermida RC, Ayala DE, Smolensky MH et al (2017) Sleep-time blood pressure: unique sensitive prognostic marker of vascular risk and therapeutic target for prevention. Sleep Med Rev 33:17-27

20. Hermida RC, Smolensky MH, Ayala DE et al (2013) 2013 ambulatory blood pressure monitoring recommendations for the diagnosis of adult hypertension, assessment of cardiovascular and other hypertension-associated risk, and attainment of therapeutic goals. Chronobiol Int 30:355-410

21. Hoevenaar-Blom MP, Spijkerman AM, Kromhout D et al (2011) Sleep duration and sleep quality in relation to 12-year cardiovascular disease incidence: the MORGEN study. Sleep 34:1487-1492

22. Hulsegge G, Loef B, van Kerkhof LW et al (2019) Shift work, sleep disturbances and social jetlag in healthcare workers. J Sleep Res 28:e12802

23. Kario K, Tomitani N, Matsumoto Y et al (2016) Research and development of information and communication technology-based home blood pressure monitoring from morning to nocturnal hypertension. Ann Glob Health 82:254-273

24. Kawada T (2016) Sleep duration and coronary heart disease mortality. Int J Cardiol 215:110 
25. Kushida CA, Chang A, Gadkary C et al (2001) Comparison of actigraphic, polysomnographic, and subjective assessment of sleep parameters in sleep-disordered patients. Sleep Med 2:389-396

26. Kyle SD, Morgan K, Espie CA (2010) Insomnia and health-related quality of life. Sleep Med Rev 14:69-82

27. LandryGJ, Best JR, Liu-Ambrose T(2015) Measuring sleep quality in older adults: a comparison using subjective and objective methods. Front Aging Neurosci 7:166

28. Lanfranchi PA, Pennestri MH, Fradette $L$ et al (2009) Nighttime blood pressure in normotensive subjects with chronic insomnia: implications for cardiovascular risk. Sleep 32:760-766

29. Mancia G (2012) Short- and long-term blood pressure variability: present and future. Hypertension 60:512-517

30. Mancia G, Verdecchia P (2015) Clinical value of ambulatory blood pressure: evidence and limits. CircRes 116:1034-1045

31. Middelkoop HA, van Dam EM, Smilde-van den Doel DA etal (1997)45-hour continuous quintuplesite actimetry: relations between trunk and limb movements and effects of circadian sleep-wake rhythmicity. Psychophysiology 34:199-203

32. Morgenthaler T, Alessi C, Friedman L et al (2007) Practice parameters for the use of actigraphy in the assessment of sleep and sleep disorders: an update for 2007. Sleep 30:519-529

33. Morgenthaler TI, Lee-Chiong T, Alessi C et al (2007) Practice parameters for the clinical evaluation and treatment of circadian rhythm sleep disorders. An American academy of sleep medicine report. Sleep 30:1445-1459

34. Muller ME, Bochud M, Pruijm Met al (2012) Effects of nighttime and daytime interval definition on blood pressure and dipping in patients referred for ambulatory blood pressure measurement. Ann Cardiol Angeiol (Paris) 61:193-197

35. O'Brien E, Parati G, Stergiou G et al (2013) European society of hypertension position paper on ambulatory blood pressure monitoring. JHypertens 31:1731-1768

36. Parati G, Stergiou G, O'brien Eet al (2014) European society of hypertension practice guidelines for ambulatory blood pressure monitoring JHypertens 32:1359-1366

37. Parthasarathy $S$, Vasquez MM, Halonen $M$ et al (2015) Persistent insomnia is associated with mortality risk. Am J Med 128:268-275.e2

38. Pepin JL, Borel AL, Tamisier R et al (2014) Hypertension and sleep: overview of a tight relationship. Sleep Med Rev 18:509-519

39. Pickering TG, Harshfield GA, Kleinert HDetal (1982) Blood pressure during normal daily activities, sleep, and exercise. Comparison of values in normal and hypertensive subjects. JAMA 247:992-996

40. Sadeh A, Acebo C (2002) The role of actigraphy in sleep medicine. Sleep Med Rev 6:113-124

41. Salles GF, Reboldi G, Fagard RH et al (2016) Prognostic effect of the nocturnal blood pressure fall in hypertensive patients: the ambulatory blood pressure collaboration in patients with hypertension (ABC-H) meta-analysis. Hypertension 67:693-700

42. Schulman JL, Reisman JM (1959) An objective measure of hyperactivity. Am J Ment Defic 64:455-456

43. Sieminski M, Partinen M (2016) Nocturnal systolic blood pressure is increased in restless legs syndrome. Sleep Breath 20:1013-1019

44. Smith MT, McCrae CS, Cheung J et al (2018) Use of actigraphy for the evaluation of sleep disorders and circadian rhythm sleep-wake disorders: an American academy of sleep medicine clinical practice guideline. J Clin Sleep Med 14:1231-1237

45. Smith MT, McCrae CS, Cheung J et al (2018) Use of actigraphy for the evaluation of sleep disorders and circadian rhythm sleep-wake disorders: an American academy of sleep medicine systematic review, meta-analysis, and GRADE assessment. JClin Sleep Med 14:1209-1230

46. Stothard ER, Mchill AW, Depner CM et al (2017) Circadian entrainment to the natural light-dark cycle across seasons and the weekend. Curr Biol 27:508-513

47. Taylor KS, Heneghan CJ, Stevens RJ et al (2015) Heterogeneity of prognostic studies of 24-hour blood pressure variability: systematic review and meta-analysis. PLoSONE 10:e126375

48. Ulu SM, Ahsen A, Akci O et al (2015) The relationship between dipping-non-dipping arterial blood pressure pattern and frequency of restless leg syndrome with related factors. Anatol J Cardiol 15:284-288

49. Van Den Eeden SK, Albers KB, Davidson JE et al (2015) Risk of cardiovascular disease associated with a restless legs syndrome diagnosis in a retrospective cohort study from kaiser permanente northern California. Sleep 38:1009-1015

50. Wang C, Bangdiwala SI, Rangarajan S et al (2019) Association of estimated sleep duration and naps with mortality and cardiovascular events: a study of 116632 people from 21 countries. Eur Heart J 40:1620-1629

51. Williams B, Mancia G, Spiering W et al (2018) 2018 ESC/ESH guidelines for the management of arterial hypertension: the task force for the management of arterial hypertension of the European society of cardiology (ESC) and the European society of hypertension (ESH). Eur Heart J 39:3021-3104

52. Zhu B, Bronas UG, Fritschi C (2018) Sleep assessment in aging adults with type 2 diabetes: agreement between actigraphy and sleep diaries. Sleep Med 46:88-94
Entwicklung kardiovaskuläre Medizin 2019

Schwerpunktheft zu wichtigen Publikationen und Daten des vergangenen Jahres

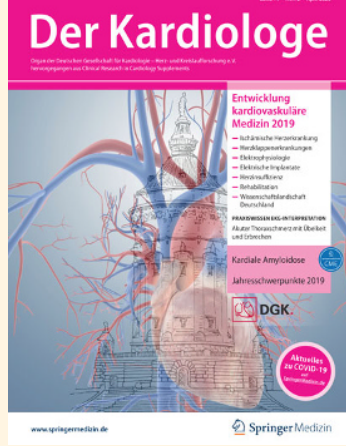

In dieser Ausgabe bieten wir Ihnen kommentierende Reviews zu neuen wichtigen Publikationen und Daten des vergangenen Jahres 2019 an.

Ob sich aus den letztjährigen Entwicklungen neue Aspekte zu verändertem diagnostischem und/oder therapeutischem Vorgehen ergeben, erfahren Sie in Der Kardiologe 02/2020 in folgenden Beiträgen.

- Jahresrückblick ischämische Herzerkrankung

- Herzklappenerkrankungen 2019

- Neuigkeiten Elektrophysiologie

- Elektrische Implantate

- Update Therapie der Herzinsuffizienz 2019

- Kardiologische Rehabilitation

- Wissenschaftslandschaft Deutschland

\section{Suchen Sie noch mehr zum Thema?}

Mit e.Med - den maßgeschneiderten Fortbildungsabos von Springer Medizin - haben Sie Zugriff auf alle Inhalte von SpringerMedizin.de. Sie können schnell und komfortabel in den für Sie relevanten Zeitschriften recherchieren und auf alle Inhalte im Volltext zugreifen.

Weitere Infos zu e.Med finden Sie auf springermedizin.de unter "Abos" 